\title{
Improving the Efficiency of an Industrial Enterprise Due to the Architectural Approach to a Complex Information Management System
}

\author{
Arevshad A. Vartanyan ${ }^{1}$ \\ ${ }^{1}$ Moscow Aviation Institute (National Research University), Moscow, Russian Federation \\ Correspondence: Arevshad A. Vartanyan, Moscow Aviation Institute (National Research University), Moscow, 4, \\ Volokolamskoe Highway, 125993, Russian Federation. Tel: 7-963-753-7110, 7-903-720-9005. E-mail: \\ danonik92@mail.ru, arevshad@mail.ru
}

Received: April 22, 2020

Accepted: May 25, 2020

Online Published: June 27, 2020

doi:10.5430/rwe.v11n3p311

URL: https://doi.org/10.5430/rwe.v11n3p311

\begin{abstract}
The use of modern technological and managerial solutions is becoming a necessary condition to increase the efficiency of industrial enterprises' production activities. The quantity and quality of their products depend fundamentally on the management system, employees' competencies, as well as their material and technical base, in which a special role belongs to information technologies (IT) that automate production processes and projects. Construction and use of complex information systems of industrial enterprise management, based on the architectural approach and the methodology of the architecture of IT will allow effectively competing in the rapidly changing market in the era of the digital economy. It minimizes the number of employees in operating and support units, and significantly increasing labor productivity, quantity, and quality of created products and services.
\end{abstract}

Keywords: architecture of the enterprise and IT, automation of business processes, business pyramid, complex information system and technology, managerial and technological innovations, and mission and strategy of the enterprise

\section{Introduction}

Improvement of business efficiency, production of quality products, making informed management decisions and maintaining strong relationships with the customers are the most important tasks for industrial enterprises in the era of the digital economy. Those companies, which adapt to changes, win in the competition (London, J. \& London, K., 2005; Utkin \& Baldin, 2005; Vartanyan, 2017).

To become such companies on the market without changing the current architecture of IT, built using software products of different generations and manufacturers, poorly integrated, is difficult, and often impossible to be achieved. To survives, adapt and successfully expand in the market, many industrial enterprises need not only to rethink their business but also to modernize its management system, to reengineer, and to automate the main business processes. Only using the architectural view of complex information systems, which automates all activities based on the designed target IT architecture and coordinated business architecture, it can effectively function in a competitive environment. It also can avoid or reduce the impact of most of the problems that arise in the process its construction (Vartanyan, 2017; Vartanyan, Golov \& Kuprikov, 2018).

Complex information system as part of an architectural approach is an automated control system, necessary for achieving the mission of the company in accordance with its vision of the future market. This system depends on business tasks and requirements, technical and IT services, covers all links and groups involved in the production, support and service. It provides work with consumers and control of business processes, ensuring effective management decisions at all levels. Its creation is carried out on the basis of the integration of existing information system in the enterprise and new applications offered on the market by various suppliers, and based on the concept of IT and enterprise architecture, investments in infrastructure, applications, information, people and business processes atomization.

However, within the architectural view, the adoption and implementation of a decision to introduce or improve complex information systems are a complex, expensive, and time-consuming task, accompanied by overcoming a multiplicity of difficulties and problems. Due to the fact that for a long time (even before the adoption of a 
universally recognized architectural view of information system), industrial enterprises have introduced and used software products for various fields of its activity poorly integrated with each other. The company's management, employees of its divisions and information services, as well as external solution integrators and application information system providers, should spend a lot time and effort to overcome these problems and create complex information system in accordance with the methodology of the architecture of the enterprise.

The current application architecture of an industrial enterprise is one of the most important components of the IT architecture. The old information system architecture sometimes does not have a comprehensive documentation to be consulted and are poorly supported by their developers due to a long time since their creation. They are written in different programming languages for various database management systems and hardware and software systems. Some problems that the company's managers face for changing the old information system architecture are associated with the reluctance of enterprise managers to change the architecture of the enterprise radically; In many cases, they often want to limit the changes to small measures to meet business needs. In addition, the introduction of a new architecture information system is always accompanied by the sabotage of enterprise employees to delay or impede the introduction of radical change in the current architecture of the enterprise (Vartanyan, 2020).

Considering an industrial enterprise through its architecture methodology is a responsible and difficult task. There is the necessity of competencies and strategic thinking and also courage and willingness to invest huge resources for a long time to build the new IT architecture of the enterprise and to abandon the old one.

\section{Theoretical Framework}

The architecture of an industrial enterprise consists of a business architecture that can be described with the help of the business pyramid (built based on the vision of the future market and the place of the company in it). At the top of that pyramid, are the mission and strategic goals of the enterprise, and at the base, the required products and services, and the logistics for their creation, including the architecture of IT.

The IT architecture ensures that applications meet the needs of the business, and the technical infrastructure meets the needs of the applications. IT strategy is the process of controlled changes in IT architecture to meet future enterprise needs. IT architecture and IT strategy are linked to the business architecture and business strategy of the enterprise, respectively (Gritsenko, 2011).

Automation of industrial enterprise activity is the implementation and use of hardware and software tools and methods for effective management of the production, the efficiency uses of its resources, departments, project groups, and marketing.

Industrial control system is a complex of technical, software, information, and organizational solutions to automate the activities of various enterprises, for example, Industrial control system in construction, industry, etc. The development of the automated control system assumes the creation of seven interconnected kinds of maintenance: technical, information, mathematical, methodical, program, linguistic and organizational.

Gradually abbreviations of the automated control system began to be replaced by enterprise resource planning (ERP) systems on which basis complex information systems is created. ERP automates the functions of resource planning, operational management and control of plans execution, analysis of economic activity, management of after-sales and warranty services, quality and transport management, sales planning, demand management, planning of materials, capacities and resources, accounting of product specifications, inventory management, accounting of order receipts, production and material flow management, management of tools, financial planning, forecasting, project and program management, supply chain and product management, etc. ERP, one of the most important components of complex information system, is an integrated product based on a single data warehouse, which allows business units to exchange information and use processed information to create decision support systems and relationships with customers.

ERP system is a logical continuation of material requirements planning (MRP) and manufacturing resource planning systems (MRP II) (Telnov, 2004; Vartanyan, Golov \& Kuprikov, 2018).

In MRP, there is the information on the needs in materials for the manufacture of products which is transformed into purchase and production orders by the formation of a sequence of production operations that allow correlating the production with the plan and minimize the amount of stocks in the warehouse. According to the data of the schedule, list of materials, composition of the product and state of stocks, the number of products for each planning period, as well as the total need for resources, is determined, which allows increasing the turnover of working capital and profitability. 
The standard is MRP II, which is based on effective capacity requirements planning for the manufacturing of products and on distributed resource planning, which eliminates the shortcomings of MRP based on the premise of unlimited resources and do not support the planning of geographically distributed business processes. MRP II allows enterprise's managers to carry out modeling and production planning in natural units and financial planning in cost units of measurement, as well as to carry out resource planning for manufacturing enterprises and service companies (Zachman, 1987).

The advantages of the model include reduction of inventory, improvement of customer service, an increase of labor productivity, reduction of purchase costs, overtime work and transport costs, and staff reduction, among others.

ERP system is complex information systems on a single database, as well as the methodology of effective planning and management of enterprise resources necessary for sales, production, procurement and accounting in the execution of customer orders.

\section{Methodology}

Complex information system is an operating environment for planning, execution and analysis of operations, describing the full cycle, from business planning to the analysis of its performance. It allows the holistic and comprehensive presentation of the company's activities and helps to reduce costs and increase the returns achieved through rapid maintenance, standardization and acceleration of production processes. Typical features of modern complex information system, designed and built on advanced enterprise architecture methodologies, are openness to platforms and database management system, increased flexibility to customers and market conditions, availability of additional automation tools, and support of multiuser network operation (Harmon, 2003).

There are two types of automated control systems in industry: automated enterprise control systems (they cover levels from enterprise to workshop) and automated process control systems (they cover levels from the workshop and the levels below them).

Introduction of the automated workplace for standard operations, formation of regulated reports on the executed works in subdivisions on different software products and absence of proper automation and systematization have led to "patchwork automation" and to the storage of the information in a set of database management system at many industrial enterprises that have caused association of isolated automated workplace in industrial control system.

There are two types of automated control systems:

- systems of the automated designing (SAD): accelerating working out of projects, reducing routine procedures and duration of the creation of new products, and also raising indicators of their quality;

- geoinformation systems: for collection, storage, search, analysis and visualization of spatial data.

SAD classify on the following: branches (mechanical engineering SAD, SAD for radio electronics, SAD in the field of architecture and building); specializations (SAD of flying machines, SAD of electric cars); target appointment for various aspects of designing: computer-aided design (CAD), computer-aided engineering (CAE), computer-aided manufacturing and product data management (PDM).

CAD is used at designing products and assumes flat (2D) and volume (3D) geometrical modeling, the analysis on settlement models, and estimation of design decisions, the reception of drawings and the design documentation, mutual transformation 2D and 3D models.

CAM is applied to technological preparation of manufacture and provides working out of technological processes, equipment, programs for machine tools with numerical programmed control, modeling of processes of processing of details, working out of the technical documentation for their manufacturing.

$\mathrm{CAE}$ is ground on the analysis, modeling and optimization of functional properties of designed devices, their systems, units and parts.

PDM is used in a mode of collective designing, with functions of management: maintenance of responsibility of executors, access rights, and conducting a database of the project.

Thus, the combination of automated workplaces allowed solving the problems of optimal planning and resource allocation at the enterprise. The effect of the complex information systems is the following: the formation of an information base for the analysis, control and planning of the enterprise, standardization and management of business processes that lead to cost optimization and creation of an effective motivation system (Vartanyan, 2019; Vartanyan, Golov \& Kuprikov, 2018).

ERP systems do not exist for constant re-planning, which became especially important with the occurrence of 
dynamic industrial systems. It does not contain any modules of analytical processing of the data and modeling of processes in real-time. In this regard, there was an expansion of functionality of ERP, which provoked the development of the following systems:

- $\quad$ ERP II, systems that provide opportunities for users to work through mobile portals;

- $\quad$ advanced planning and scheduling systems, covering the interaction of the enterprise with customers at all stages of the product life cycle;

- customer synchronized resource planning systems;

- computer-integrated manufacturing systems, which involve the concept of computerized production, in which to the traditional ERP functions are added computer-aided design, and operational management of workshops and equipment;

- manufacturing execution systems (MES), consisting of automated production management systems (automated process control systems);

- customer relationship management systems;

- $\quad$ supply chain management systems, based on the logistics chain management;

- on-line analytical processing (OLAP) technologies, which involve the analytical processing of multidimensional data in real-time.

The information gap between automated enterprise control systems (which automatizes the strategic level of production management) and the automated process control systems closes the automated production process control systems (APPCS) or MES, which monitor in real-time the production processes of finished products, connect the technological parameters of production and performance indicators. The main functions of APPCS are as follows: control of the state and distribution of resources; operational planning; production scheduling; management of production documents, staff, documents, product quality, production processes and funds; establishment of links between staff and equipment, between production and suppliers, consumers, employees of subdivisions; etc.

There are the following two types of production enterprises by type of production processes: discrete (production, in which raw materials for the creation of the product undergoes more than one process with the interruption of the technological process, including custom production) and continuous (set of continuous technological processes, organized in the form of a production line, site, shop or enterprise as a whole).

Thus, proceeding from the concept of the architecture of the application, it is possible to represent complex information systems as four levels responsible for support the consideration of problems related to strategic, tactical and operative management of the enterprise:

- MES is the automated production management system for solving problems of synchronization, coordination, analysis and optimization of production;

- $\quad$ ERP is the system of planning and management of enterprise resources;

- OLAP is the analysis of data and their analytical processing in real-time, with the compilation of dynamic reports on sales, marketing, and management purposes.

Depending on the specifics and strategy of the enterprise, we also use:

- business performance management, which connects the company's mission, strategy, goals, plans and budgets;

- enterprise asset management, which is a fixed asset management system;

- balanced scorecard, which is a balanced system of company's indicators;

- activity-based costing, which is a process-oriented method of distribution of overhead costs;

- economic valued added, which is a system of value-added accounting, and comparison of alternative investments in the project;

- collaborative manufacturing execution system (c-MES);

- Docflow, which is an electronic document management system.

MES systems help to understand, how within the given timeframe and resources to make the production and ERP systems realize volume planning (when and how many products should be made). MES systems are integrated with 
an industrial level and have the information, which allows correcting and optimizing manufacture with a fast reaction on events and deviations from planned tasks. They are a link between financial, economic and operative activity of the departments of the enterprise.

Production management is based on the solution of four important production tasks: formation of the volume and nomenclature plan, the balance of production capacities, preparation of production schedules, and grouping of equipment and assembly units.

The first two tasks are solved with the help of ERP, and the rest with the help of MES. The integration of these systems within the framework of the complex information systems will allow for planning and managing production effectively, transferring detailed plans and reports to the heads of its structural subdivisions.

Complex information system also provides the following functionality and integration with application systems:

- management information system for decision-making;

- supply chain management;

- customer relationship management;

- PDM;

- finite resource planning;

- stand-alone configuration engine;

- $\quad$ sales \& service management;

- product and process engineering;

- electronic commerce for interaction with suppliers and customers;

- supervisory control and data acquisition, which is a real-time process control system and remote data collection;

- human machine interface;

- business intelligence, used to analyze information about the company and its environment and to collect information for decision making;

- advanced planning and scheduling;

- planning of production tasks and materials, production plan and planning of capacity utilization, sales and demand forecast, pushing an urgent order into production schedules, re-planning;

- just in time, allowing to ensure the receipt of all materials, components and semi-finished products in the required quantity, at the right place and time for production or assembly of products, etc.

\section{Results}

Here there are the main problems associated with the implementation and use of IT that industrial enterprises face:

- moral aging of IS. As an example, at the majority of Russian industrial enterprises, the existing information systems solve individual production problems. At the same time, their own serious developments, in which there are huge databases with production information, are outdated and do not meet the requirements of the time;

- patchwork automation. Many enterprises have a different number of information system that are not compatible with each other, which leads to patchwork automation and their inefficient use. The development of information system at the stages of the product life cycle was carried out unevenly, and it is necessary to create complex information systems to close the gaps in the information chains throughout the life cycle products. Therefore, the primary task for enterprises is to master the means of designing and preparing the production of new products and electronic document management, which will allow obtaining initial data for the tasks of planning and managing production and resources;

- lack of design approach. Using IT as an operation to purchase hardware and software does not take into account the share of costs (up to 70\%) for their implementation, regardless of whether they are carried out by the 'customer's IT service or by integrators;

- lack of a centralized and integrated approach to enterprise automation. Lack of centralized management of IT tasks leads to the collapse of information system implementation, as a result of conflicts between 
departments, lack of personal responsibility and coordinated efforts to overcome difficulties, inhibition of managerial decision-making, and increase the period for IT implementation;

- underestimation of the psychological aspects of the transition to new IT architecture. The transition to the target complex information systems involves certain reorganization and automation of the main business processes of the enterprise. Often the cause of innovation is the presence in the team of active people who are trying to improve the work of the company, and also the unwillingness of some employees to change the established order of things. Accordingly, there is an underestimation of the value of resistance to innovation (Vartanyan, 2020);

- lack of a regulatory framework for complex information system. Automation of an enterprise often relies on work rules that reflect the interests of IT companies involved in the implementation of IT architecture rather than the interests of the customer, who, after introducing IT, faces the problems of their administration and use, without the necessary regulations and specialists. This leads to the fact that automation does not give the expected effect. Lack of quality management standards often leads to low IT projects and problems: difficulties in planning activities; lack of uniform reporting forms; difficulties in identifying the causes of failures in the work of units, and others. Lack of international trade standards that require IT support for life cycle products raises many questions regarding interaction with foreign partners related to building production, training, document management, among others.

Summarizing the impact of the problems and using the 'author's experience in implementing and operating complex information systems for various enterprises, there are the following disappointing data on the implementation of IT projects: only $15-20 \%$ of them finish on schedule; $30-35 \%$ of them do not achieve their goals; $50 \%$ of them increase in price by more than $100 \%$; in completed projects, only $60 \%$ of the requirements are implemented; $60 \%$ of IT investments are unprofitable or have no effect. Among the reasons for this state of affairs there are the following ones: insufficient attention of managers to automation issues; their lack of clear goals for implementing IT project; chaotic business processes that are not amenable to automation; employees' unwillingness to change; instability of legislation; lobbying for unsecured IT projects; low qualifications of personnel for work in complex information system; insufficient IT funding due to an incorrect assessment of the amount of upcoming implementation work (Vartanyan, 2017; Utkin \& Baldin, 2005).

The way out of such a difficult situation lies in the joint efforts of all interested parties: authorities, state standards, IT companies, scientific institutions, and manufacturing enterprises.

One of the directions for solving these problems is the development of regulatory documents for the implementation of IT projects, the use of which will allow doing the following:

- correctly formulating goals and requirements for production automation;

- improving the quality of project implementation and decisions;

- defining roles in the IT project team:

- $\quad$ using the experience of other enterprises.

The application of normative base and standards in the field of IT projects will help to solve problems requiring high professional knowledge of IT specialists in the field of systems and data integration and should also provide a qualitatively new level of organization of the processes of designing, manufacturing and operating complex products, improve the efficiency of process implementation life cycle of products and increase their competitiveness.

The development of IT requires the construction of a new IT architecture, including the architecture of IT services that support the life of the enterprise. There is the task of building a corporate IT architecture for realizing a model of a digital enterprise, in the center of which is a database: an environment for storing and processing corporate information for all IT tasks and applications: design, technological, production, among others.

This approach is a reflection of the new paradigm of developing new products and doing business: integrating internal and external information flows, real-time management, and mastering analytic methods and tools in the interests of strategic and sustainable development of the enterprise.

The creation of an organizational IT structure should allow working with the company's IT assets, methodologically support the corporate data model and manage the information on the life cycle of the products. So, it is necessary to compose the existing non-standard IT components into an adequate and justified structure, select and integrate all applications, provide IT products with all the tasks and stages of the life cycle of the products and resource management of the enterprise, and also consider the organization and stages of the gradual transition to a new (target) 
IT architecture. It is also necessary to know, how it will fit into the existing IT landscape of the enterprise.

The most important tasks for many industrial enterprises are transferring all IT services to a modern technology platform and programming tools and developing a strategy for switching to innovative enterprise and resource management tools for ensuring the continuity of existing systems and preserving the accumulated databases. Therefore, the highest demands are placed on the implementation team, the selection of performers with a deep understanding of the subject area, as well as the ability to manage complex IT projects.

Mastering IT is a process of interaction between the entire enterprise team as part of its professional activities. The formation of information system and its future users should be subordinate to one thing: solving the strategic tasks of the company. Therefore, to obtain the desired result, it is necessary to have detailed IT projects and quality management structure for the processes of their implementation at the level of the 'company's management.

Complex information system, built not as an improvement of the existing system, but as the creation of a new unique solution that takes into account the best industry and world practices, should embrace and bring together tools and methods used to improve information support and ensure the production and business activities of the company. Therefore, it is necessary to include the IT service in the organizational structure of the enterprise as a basic life support system and a general strategy for its development, and give for its leader a high status of deputy head.

The effect of the introduction of this complex information systems based on the methodology of enterprise architecture is manifested primarily in well-organized production. At the same time, adjusting the structure of the enterprise should be carried out gradually: the development and implementation aim of automated business processes are to reduce the risk of psychological barriers for innovations among employees.

As a result of the introduction of complex information system, the following things are ensured: data unity of all types of accounting; implementation of prescribed management procedures; operational control over the costs of enterprise resources; high degree of independence of enterprise management from the individual characteristics of managers; compliance with international management accounting standards, increasing the capitalization of the enterprise and, consequently, its investment attractiveness.

The choice of a specific information system presented by numerous domestic and Western developers, as well as setting goals for enterprise automation, must be carried out based on the framework of long-term strategic planning, the company's mission, available resources, and time. Although when choosing information system, it is impossible to take into account all possible effects due to many factors; it is necessary to cover at least all quantitative and qualitative effects obtained as a result of the operation of the selected systems.

The main benefits from the implementation of complex information systems are the following:

- reduction of operating and managerial costs;

- saving of working capital;

- reduction of product sales cycle;

- reduction of commercial costs and receivables;

- increase in the turnover of funds;

- improvement of the quality control of production costs due to cost detailing;

- inventory optimization;

- sales increase due to increase customer service quality.

\section{Discussion}

There is a lot of information system for automating the activities of industrial enterprises, but their functionality and popularity is different. In addition, the information management structure of a manufacturing enterprise can also be represented by a number of levels responsible for supporting the tasks, by including application information system responsible for operating on the Internet. Without portal solutions, cloud services, payment systems, technology of on-line stores, virtual and augmented reality, contact centers and other applications, the work of modern manufacturing companies in the digital transformation are unthinkable.

The introduction of complex information systems involves making the automation goals and, in accordance with them, selecting suitable information system for automating the main business processes of the enterprise, as well as the possibility of their integration with other systems. After designing complex information system, we can make a preliminary calculation of the expected total cost of ownership of the new solution, as well as the necessary changes 
in the work of the different units. Having designed the system, taking into account the selected architecture of IT, we can proceed to the procurement of the selected complex information systems and component solutions. By installing software, setting up equipment and databases, transferring information from the existing information system of the enterprise to the new system, completing the implementation and testing process, we can proceed to pilot production and to industrial operation abandoning old information system.

Implementation and operation of complex information systems projects are fraught with great risks. Failure to meet the project deadlines and cost overruns are usually present in any project. The cause of these risks is the company's unwillingness to implement all components of IT architecture project. There can be the following main risks: functionality of the selected complex information systems is inadequate to the automated business process; excess of estimates and terms for the implementation of the system; changing the goals of the enterprise and its business priorities; and decrease in the efficiency of it. The purpose of risk management is to minimize negative factors that lead to problems and difficulties in the enterprise. The risk management process involves identifying, analyzing, and assessing project risks, applying selected methods, and evaluating risk management results.

An important aspect of the implementation of any project is the assessment of the results of the work performed, the analysis of which can answer about the nature of the problems identified.

Complex information system is a complex software product that can be implemented only by the joint efforts of the enterprise top managers and staff and the developer. In the field of IT, the success of the project largely depends on the professional competence of specialists and managers, as well as by the support given to the project by the top management of the enterprise.

When trying actually to implement information system, one often encounters a situation of system rejection by enterprise personnel, their reluctance and sabotage at all stages of the process of creating and implementing a designed solution.

Sometimes the employees of the automated control system department of the enterprise initially perceive the new system negatively. A clear understanding by the enterprise management of the goals and objectives for the implementation of which complex information systems is being introduced, willingness of a joint team of specialists both from the complex information systems developer and the enterprise, desire and readiness of the enterprise management to make the changes in their management processes and consistency in the implementation of such changes, will result in a successful implementation and productive use of the constructed solution.

The development of modern technologies leads to an increase in the complexity of implementation of information system architecture, which incorporates technical innovations and new trends and solutions in the field of business.

IT must be used carefully as a tool to improve business performance. A positive effect is achieved only if the management of the enterprise has a clear idea of how to solve the set goals and objectives.

Thus, for the successful completion of IT project, it is necessary to develop a common strategy for enterprise automation within the architectural view, full accounting and control of possible risks, development of a project and a detailed plan for its implementation, as well as the interest of senior management in the work of complex information system.

\section{Conclusion}

Complex information system for managing an industrial enterprise is expensive and need a lot of time and resources for their implementation and maintenance (including infrastructure, software license, system design, automation of production processes, application customization and refinement of their functionality) and also for implementation, beta-testing and production maintenance and employee training. In addition, the process of implementation and operation of the complex information systems has a lot of risks that must be foreseen, and we must take measures to eliminate the reasons that cause them.

A clear definition of the goals of implementing complex information system and interest in this project of the top management of an enterprise is a starting point in assessing the appropriateness of the costs of automating its management activities.

In particular, complex information system, built with the using the methodology of IT, allows improve quality and efficiency of the management of the enterprise and each structural unit and project, product, and labor, it also helps to company revenues, and help to reduce costs. The architectural view of complex information systems is very relevant in the modern era of the general digitalization of business processes.

Based on the personal experience of the author in managing projects in industrial enterprises of energy, chemical, 
food, mining companies, organizations providing telecommunication services, as well as the practice of other specialists in the automation of domestic industrial enterprises using the "architectural" approach, there are the following important conclusions about what built complex information systems allows: it allows reducing the cost of products by $20-40 \%$ and defect by $10-20 \%$, inventory and warehouse by $15 \%$, product quality costs by $25-40 \%$, outsourcing and IT development costs by $25-45 \%$, time of collecting and processing information for decision-making by $50 \%$, improving specification accuracy and delivery times by $30-50 \%$; using efficiently production capacities and production planning by $20-40 \%$; accelerating the time for launching new products on the market by $20-40 \%$; increasing sales and profitability of the company by $10-20 \%$; reducing costs and time for preparing commercial offers and pricing by 20-40\% (Vartanyan, 2019; Vartanyan, Golov \& Kuprikov, 2018).

\section{References}

Gritsenko, Yu, B. (2011). Enterprise Architecture: Tutorial. Tomsk: Tomsk State University of Control Systems and Radio-electronics.

Harmon, P. (2003). Developing an Enterprise Architecture. Business Process Trends.

London, J., \& London, K. (2005). Information Systems Management (7th ed.). St. Petersburg: Piter.

Telnov, Yu, F. (2004). Business process reengineering. Component Methodology. Moscow: Finance and statistics.

Utkin, V. B., \& Baldin, K. V. (2005). Information Systems and Technologies in Economics: Textbook for High Schools. Moscow: UNITY-DANA.

Vartanyan, A. A. (2017). Information Management. Textbook (2 ed.). Moscow: Dobroe Slovo.

Vartanyan, A. A. (2019). Introduction to enterprise architecture. Tutorial. Moscow: Sputnik.

Vartanyan, A. A. (2020). Technology of convergence of team-coalition and administrative control of industrial enterprise. Amazonia Investiga, 9(26), 423-431.

Vartanyan, A. A., Golov, R. S., \& Kuprikov, M. Yu. (2018). University resource and service training centers for industrial enterprises. Economics and management in mechanical engineering, 2, 44-48.

Zachman, J. A. (1987). A framework for information system architecture. IBM System Journal, 26(3), 276-292. 